the slow changes in macromolecular interactions which seem to occur when reduced and alkylated human $\gamma$-globulin is treated with acetic acid (reported by K. B. Cooke and P. Jayawardene of Westminster Medical School) provided much food for thought.

Dr C. B. Anfinsen (National Institutes of Health, Bethesda) reviewed the progress of his multi-faceted assault on staphylococcal nuclease, and discussed this work in relation to general principles. One of the outstanding problems of molecular biology is the mechanism by which disordered polypeptide chains fold into biologically active structures. Anfinsen favours the viow that sections of the peptide backbone which are ordered in the native protein act as nucleating centres in this process.

Evidence is accumulating to support the generalization that phosphorylated residues in milk and egg phosphoproteins occur in clusters: this now gains further support from the determination (by Drs W. D. Annan and W. Manson of the Hannah Dairy Research Institute, Ayr) of the sequence of the $N$-terminal pentacosapeptide of $\beta$-casein (variant $A_{1}$ ), which contains four phosphoscrine residues, three of them contiguous. Dr A. Anastasi (Farmitalia, Milan) reported the sequence and pharmacology of phyllomedusin, a kinin peptide closely related to physalaemin.

In contrast, the contribution from Dr S. Bajusz (Research Institute for Pharmaceutical Chemistry, Budapest) was concerned with synthesis, and consisted of a progress report on the synthesis of a fragment of human growth hormone containing sixty-seven residues. The strategy adopted involves fragment condensation by the azide method with minimal side chain protection to facilitate purification of intermediates and reduce solubility problems with large fragments. Those engaged in the application of peptide synthesis to enzymes will await eagerly the publication of the practical datails of this work.

\section{SOLID EARTH}

\section{Eurth Sciences Still Growing}

\section{from our Geophysics Correspondent}

Geophysics had such a good time in the 1960s that many prophets of doom were prepared to predict that the subject could not but decline to nit-picking in the 1970 s. With so much action and so many devclopments, what was going to be left but a sweeping up operation? A gathering of 700 at Harvard on April 16 to 18 must have departed well satisfied that their jobs were not in danger and the seventy-five students that NSF sponsored (an imaginative and praiseworthy gesture) were probably more than ever convinced that there is plenty for them.

The occasion was in honour of Professor Francis Birch, retiring professor of experimental geology at Harvard, and the theme of the meeting was the nature of the solid earth. Birch succeeded Bridgman at Harvard and took the high pressure work in progress there far into the geological field. The possibility of simulating conditions in the Earth's mantle was early appreciated by Birch and his studies of rocks which are possible candidates for the mantle proved classic. He went beyond simple experimental observations, however, and formulated a relationship between elastic parametors and densities. He also adopted finite strain theory in an effort to reconcile his observations with solid state physics concepts. It is tribute to his sound reasoning that laws he proposed twenty years ago are still regarded as an excellent approximation and widely used. The advent of data often wrecks geological/geophysical theories. Birch has had more success.

Many of the speakers had been pupils of Birch and many of the contributions sprang directly from his interests. Drs D. L. Anderson (California Institute of I'echnology) and O. L. Anderson (Columbia) addressed the question of where present day studies of elastic constants at high pressures and the associated mineralogy are leading in terms of realistic Earth structures. The mean atomic weight of the mantle seems a well determined number now of between 21 and 22 . This is directly inferred from seismic velocity/density distributions yielded by the Earth and by laboratory determinations. Phase changes in the mantle grow in interest and Dr A. E. Ringwood (Australian National University) gave a detailed exposition of the state of knowledge, including the appealing germanate-silicate analogue methods. It is likely within the next year or two that seismic arrays will give unambiguous evidence both of the presence of these transitions (of which the two major ones are at $350 \mathrm{~km}$ and $600 \mathrm{~km}$ ) and also of the degree of sharpness.

The inversion of geophysical data to Earth structure is a topic beginning to return to the foreground again. Uniqueness has always been a problem and the very important work of Drs F. Gilbert and G. Backus (La Jolla) was presented for the case where inversion is further hindered by crrors in data. As a result of this work it is becoming easier to see what statements about the Earth's interior are meaningful and what detail can be resolved. A completely different approach is that of Dr F. Press (Massachusetts Institute of Technology), who allows a computer to generate millions of Earth models but retain only those consistent with a set of seismic constraints. The Monte Carlo method raises some interesting and widely debated points about density distribution in the upper mantle. The conventional value of $3 \cdot 3 \mathrm{~g} / \mathrm{cc}$ for the top of the mantle is questioned-values 5 per cent higher seem to be called for.

The remarkable success of plate tectonics as a unifying rigorous theory of sea floor spreading and continental drift was reflected in several contributions. Dr D. McKenzie (University of Cambridge) added the Red Sea and Mediterranean to the list of regions where the plate concept seems valid and useful. He and Dr D. Griggs (University of California, Los Angeles) were both concerned with the geodynamic problems of a descending cold plate beneath island arcs. The questions of driving forces, earthquake mechanisms and the effect of these plates on seismic observations remain very fertile fields for study.

Surveys of some recent developments in marine geophysics were given by Drs H. W. Monard (La Jolla) and $\dot{M}$. Ewing (Columbia). A point of considerable interest here is the resurgence of interest in the sedimentary record. The vast amount of scismic profiler data now available in addition to the superb JOIDES results is undoubtedly leading to a growth in marine sedimentary geology. Plate tectonics is also posing a challenge to land geology in that the grosser features of the Farth-the Rockies, Himalayas, Urals and Alps-might well bo explained in terms of earlier plate collisions. 